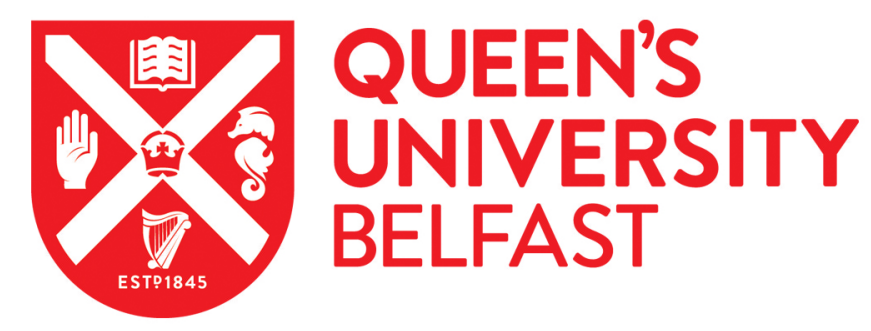

\title{
Influence of an arbuscular mycorrhizal fungus on competition for phosphorus between sweet orange and a leguminous herb
}

Yao, Q., Zhu, H. H., Chen, J. Z., \& Christie, P. (2005). Influence of an arbuscular mycorrhizal fungus on competition for phosphorus between sweet orange and a leguminous herb. Journal of Plant Nutrition, 28(12), 2179-2192. https://doi.org/10.1080/01904160500323537

Published in:

Journal of Plant Nutrition

Queen's University Belfast - Research Portal:

Link to publication record in Queen's University Belfast Research Portal

\section{General rights}

Copyright for the publications made accessible via the Queen's University Belfast Research Portal is retained by the author(s) and / or other copyright owners and it is a condition of accessing these publications that users recognise and abide by the legal requirements associated with these rights.

Take down policy

The Research Portal is Queen's institutional repository that provides access to Queen's research output. Every effort has been made to ensure that content in the Research Portal does not infringe any person's rights, or applicable UK laws. If you discover content in the Research Portal that you believe breaches copyright or violates any law, please contact openaccess@qub.ac.uk. 


\title{
Influence of an Arbuscular Mycorrhizal Fungus on Competition for Phosphorus Between Sweet Orange and a Leguminous Herb
}

\author{
Q. Yao, ${ }^{1}$ H. H. Zhu, ${ }^{2}$ J. Z. Chen, ${ }^{1}$ and P. Christie ${ }^{3}$ \\ ${ }^{1}$ College of Horticulture, South China Agricultural University, Guangzhou, China \\ ${ }^{2}$ Guangdong Institute of Microbiology, Guangzhou, China \\ ${ }^{3}$ Agricultural and Environmental Science Department, Queen's University Belfast, \\ Belfast, UK
}

\begin{abstract}
Grass or herb intercropping with trees is widely practiced as an orchard-floor management strategy, but nutrient competition from grass species can inhibit the growth of intercropped fruit trees. Two experiments were conducted to investigate whether inoculation with the arbuscular mycorrhizal (AM) fungus Glomus versiforme can alleviate such competition and thus promote the growth of intercropped fruit trees by increasing soil nutrient exploitation. In the first experiment, intercropping was established in rhizoboxes containing sweet orange (Citrus sinensis) and the leguminous herb Stylosanthes gracilis inoculated with the AM fungus. Mycorrhizal inoculation did not appear to decrease competition, but increased the biomass of the herb much more than that of sweet orange. Inoculation had little effect on phosphorus $(\mathrm{P})$ content of sweet orange, but significantly increased that of the legume roots. The AM fungal contribution to $\mathrm{P}$ uptake of the herb was twice that of sweet orange. Lateral roots of the herb tended to branch horizontally, with a large proportion entering the soil volume occupied by sweet orange; AM inoculation enhanced this effect. In Experiment 2, growth of the plants in monoculture revealed that the mycorrhizal dependency of the legume was much higher than that of sweet orange. It is suggested that mycorrhizal dependency can have a large influence on the role of the AM fungus in mediating competition in an intercropping system, and that fruit trees with high mycorrhizal dependency, together with a grass or herb with low mycorrhizal dependency, may be the optimum intercrop combination in orchards.
\end{abstract}

Keywords: AMF, sweet orange, legume, competition

Received 30 July 2004; accepted 23 May 2005.

Address correspondence to Q. Yao, Department of Pomology, College of Horticulture, South China Agricultural University, Wushan Road, Guangzhou 510642, P.R. China. E-mail: yaoqcn@yahoo.com.cn 


\section{INTRODUCTION}

Grass intercropping has been a popular management practice in orchards for several decades (Butler, 1986) and, compared with conventional floor management, increases soil aggregate stability and decreases soil temperature in summer (Walsh et al., 1996). Increased soil organic-matter content and macroporosity (pores $>1 \mathrm{~mm}$ in diameter) were demonstrated by Welker and Glenn (1988) in a young peach orchard intercropped with perennial ryegrass; other advantages of intercropping in orchards have also been well documented (Butler, 1986; Klik et al., 1998; Skroch and Shribbs, 1986). These effects have led to a worldwide increase in the replacement of conventional orchard-floor management with intercropping systems, especially in the establishment of organic fruit production.

Despite these benefits of intercropping, nutrient competition between the root systems of grass and fruit crops can occur, and competition for nitrogen (N) may be particularly important (Haynes, 1980). Tworkoski and Glenn (2001) reported that the foliar $\mathrm{N}$ concentrations in two peach cultivars declined significantly when the trees were intercropped with eight grass species, and this drop led to large reductions in annual vertical and lateral shoot growth and annual fruit yields. In a vineyard with perennial ryegrass intercropping, grape foliar concentrations of 11 nutrients measured, including N, sulfur (S), calcium $(\mathrm{Ca})$, manganese $(\mathrm{Mn})$, iron $(\mathrm{Fe})$, and boron $(\mathrm{B})$, were greatly reduced due to competition with the grass (Tan and Crabtree, 1990). Results from another vineyard experiment indicated that grape growth suppression by interplanted crops tended to occur in relatively dry years (Pool et al., 1990). Mowing of cover crops is commonly practiced to reduce their competitive ability (Skroch and Shribbs, 1986) but this strategy entails additional labor costs.

It is well established that arbuscular mycorrhizal (AM) fungi are beneficial to host plants in nutrient uptake from soil volume (Smith and Read, 1997). Following increased nutrient uptake by AM fungi, plant growth is usually enhanced greatly. Many investigations have shown that AM fungi live in orchard soil and form symbioses with fruit trees of 54 orders (Hu, 1998). Experiments have demonstrated that citrus plants may benefit much from the formation of mycorrhiza, in both greenhouse pot culture (Graham et al., 1982) and under field conditions (Camprubi and Calvet, 1996), because of the sparse distribution of root hair for this plant specie. Peng et al. (1993) found that plant growth of 'Volkamer' lemon could be increased 2.27 times by Glomus intraradices $92 \mathrm{~d}$ after inoculation. Research also indicated that different growth responses to AM fungi occurred between different citrus species, even between different varieties. For example, mycorrhizal dependency of seven banana cultivars varied from 5\% to 55\% (Declerck et al., 1995). Therefore, AM inoculation may be an effective alternative strategy to improve the nutrient competitive ability of fruit trees, and consequently to alleviate the nutrient competition from cover crops.

The present study was based on the hypothesis that growth of fruit trees may be promoted by AM fungal inoculation in an intercropping system on a soil 
of low fertility. One rhizobox experiment was designed to investigate whether or not inoculation with the AM fungus Glomus versiforme ameliorates nutrient competition from an herb, Stylosanthes gracilis, intercropped with sweet orange and any consequent effects on sweet orange yield. A second experiment in which the two plant species were grown in pots in monoculture was conducted to determine the mycorrhizal dependency of the two plant species.

\section{MATERIALS AND METHODS}

\section{Plant Species and AM Fungal Inoculum}

Sweet orange [Citrus sinensis (L.) Osbeck. cv. 'Luogang'] was chosen as the experimental fruit tree because it is widely grown in south China. The legume herb Stylosanthes gracilis Kunth (cv. 'Graham') was selected as the intercropping species because of its tolerance to high temperatures and widespread use in intercropping with fruit trees in south China. Glomus versiforme (Karsten) Berch was used to establish AM colonization. Inoculum consisted of mycorrhizal root fragments (Zea mays L.) and soil from pot culture using maize as the host plant.

\section{Experiment 1}

Rhizoboxes, each $30 \mathrm{~cm}$ long $\times 3 \mathrm{~cm}$ wide $\times 40 \mathrm{~cm}$ high (Figure 1 ), were employed to grow the two intercropped plant species. Sweet orange seeds of similar size were sown in autoclaved perlite and seedlings at the two-three leaf stage were transplanted into the rhizoboxes. Seeds of $S$. gracilis were immersed in water at $60^{\circ} \mathrm{C}$ for $5 \mathrm{~min}$ before sowing in the rhizoboxes. Then $4 \mathrm{~kg}$ of growth substrate, a 2:1 (v/v) mixture of autoclaved red soil and river sand amended with basal fertilizer $\mathrm{N}\left(200 \mathrm{mg} \mathrm{kg}^{-1}\right)$ and $\mathrm{K}\left(100 \mathrm{mg} \mathrm{kg}^{-1}\right)$, were placed in each rhizobox. Red soil is a ubiquitous soil type in south China and is characterized by low nutrient status and heavy texture. One sweet orange seedling was transplanted into one half of the rhizobox and 10 seeds of $S$. gracilis into the other half, as shown in Figure 1. Three treatments were established in triplicate: Low P (no phosphorus (P) fertilizer applied), Low P with $10 \%$ (w/w) AM fungal inoculum, and High $\mathrm{P}$ (50 $\mathrm{mg} \mathrm{P} \mathrm{kg}^{-1}$ applied). The plants grew in a greenhouse without supplementary illumination for four months.

\section{Experiment 2}

A second pot experiment was established to compare the growth response of the two plant species to AM inoculation in monoculture. Preparation of sweet orange seedlings and $S$. gracilis seeds was as described above, and $G$. versiforme inoculum was used again. Each pot received $450 \mathrm{~g}$ autoclaved soil/sand substrate and one sweet orange seedling or about 50 seeds of $S$. gracilis were transplanted 


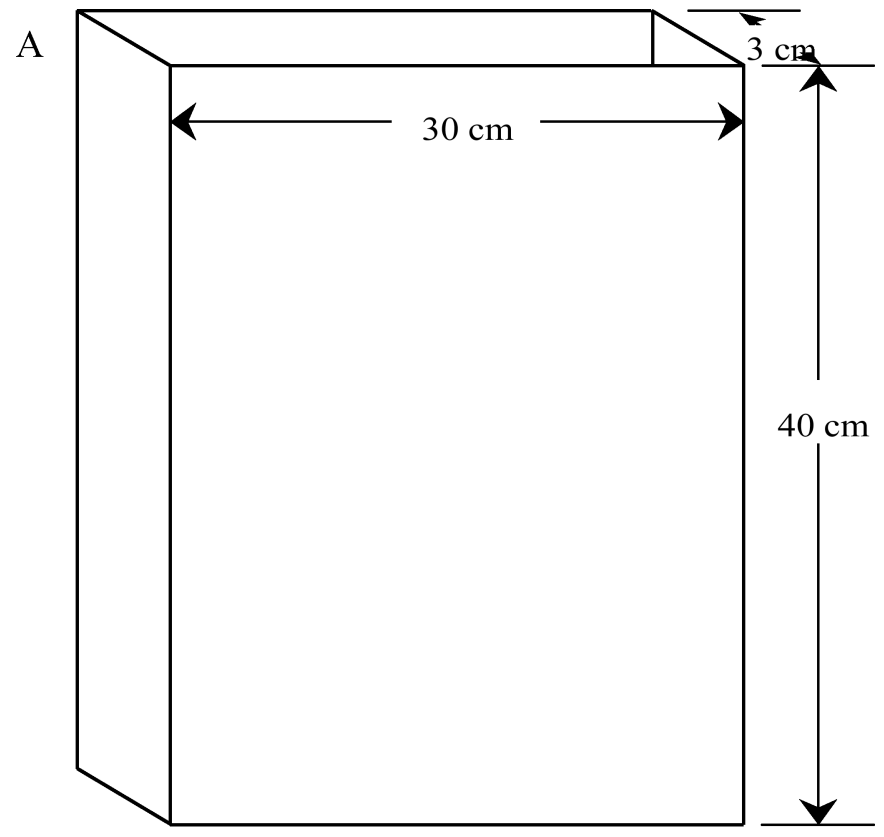

B

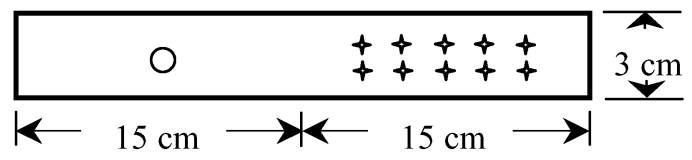

Sweet orange

$\downarrow \quad$ S. gracilis

Figure 1. Diagrammatic representation of the rhizoboxes used in the first experiment. A: dimensions of rhizobox; B: arrangement of sweet orange and S. gracilis plants (viewed from above).

into each pot. After $10 \mathrm{~d}$ the $S$. gracilis seedlings were thinned to twenty plants. Pots inoculated with $G$. versiforme and uninoculated pots were set up and there were four replicates per treatment. Plants grew for two months and plant biomass, root colonization rate, and $\mathrm{P}$ nutrition were determined as described above.

\section{Plant Harvest and Measurements}

At the end of the first experiment, the shoots were harvested and the rhizoboxes were carefully dissected. Intact soil volumes were cut vertically into two halves. Roots of the two plant species were carefully removed from the two sides and 
carefully cleaned free of soil with tap water. Roots were cut into $2 \mathrm{~cm}$-long segments and total root length was estimated using Newman's (1966) gridintersection method. Shoots and roots were oven-dried for $48 \mathrm{~h}$ at $70^{\circ} \mathrm{C}$ and ground, and $\mathrm{P}$ concentrations were determined by the molybdenum blue colorimetric method (Thomas et al., 1967). The mycorrhizal percentage contribution to $\mathrm{P}$ uptake was calculated as follows: [(P uptake by mycorrhizal plants $-\mathrm{P}$ uptake by non-mycorrhizal plants in low-P soil)/P uptake by mycorrhizal plants] $\times 100$. The percentage contribution of $\mathrm{P}$ fertilizer application to plant $\mathrm{P}$ uptake was calculated as follows: [(P uptake by non-mycorrhizal plants in $\mathrm{P}$-amended soil - $\mathrm{P}$ uptake by non-mycorrhizal plants in low-P soil)/P uptake by non-mycorrhizal plants in P-amended soil] $\times 100$. After staining with trypan blue (Phillips and Hayman, 1970), mycorrhizal colonization rates were estimated using the method of Koske and Gemma (1989). Mycorrhizal dependency (Plenchette et al., 1983), $\mathrm{P}$ uptake, and AM contribution to plant $\mathrm{P}$ nutrition were also calculated.

\section{Statistical Analysis}

All data were analyzed using the SPSS 11.0 statistical package (SPSS, Inc., Chicago, IL). Treatment means in the first experiment were compared by least significance difference (LSD) at the 5\% level following one-way analysis of variance (ANOVA). Statistically significant differences between means in the second experiment were determined by paired t-test $(P<0.05)$.

\section{RESULTS}

\section{Effect of AM Inoculation on Biomass of Intercropped Plants}

Table 1 shows that the shoot biomass of sweet orange was significantly increased by $\mathrm{P}$ fertilizer application but not by AM inoculation. However, biomass of $S$. gracilis shoots and roots was significantly enhanced by both $\mathrm{P}$ application and AM inoculation.

\section{Effect of AM Inoculation on Phosphorus Status of Intercropped Plants}

Phosphorus concentrations in both plant species were significantly higher with $\mathrm{P}$ fertilizer application, but AM inoculation showed contrasting effects on the two plant species (Table 2). When no P fertilizer was applied, no significant difference in shoot or root $\mathrm{P}$ concentration was observed between non-mycorrhizal and mycorrhizal sweet orange plants; however, significant differences in root $\mathbf{P}$ concentrations were observed between non-mycorrhizal and mycorrhizal $S$. gracilis plants. 
Table 1

Influence of AM inoculation and P fertilizer on biomass ( $\mathrm{g}$ ) of intercropped sweet orange and $S$. gracilis

\begin{tabular}{lllllllll}
\hline & \multicolumn{3}{c}{ Sweet orange } & & \multicolumn{3}{c}{ Stylosanthes gracilis } \\
\cline { 2 - 4 } Treatment & $\begin{array}{c}\text { Shoot } \\
\text { DW }\end{array}$ & $\begin{array}{c}\text { Root } \\
\text { DW }\end{array}$ & $\begin{array}{c}\text { Root-to- } \\
\text { Shoot ratio }\end{array}$ & & $\begin{array}{c}\text { Shoot } \\
\text { DW }\end{array}$ & $\begin{array}{c}\text { Root } \\
\text { DW }\end{array}$ & $\begin{array}{c}\text { Root-to } \\
\text { Shoot ratio }\end{array}$ \\
\hline Low P & $0.96 \mathrm{a}$ & $0.99 \mathrm{a}$ & 1.05 & & $6.43 \mathrm{a}$ & $1.43 \mathrm{a}$ & 0.22 \\
Low P + AM fungus & $1.24 \mathrm{ab}$ & $1.18 \mathrm{a}$ & 0.95 & & $13.05 \mathrm{~b}$ & $2.55 \mathrm{~b}$ & 0.20 \\
High P & $1.54 \mathrm{~b}$ & $1.22 \mathrm{a}$ & 0.80 & & $12.64 \mathrm{~b}$ & $2.45 \mathrm{~b}$ & 0.19 \\
\hline
\end{tabular}

Values are the mean of three replicates. Values in the same column followed by the same letter are not significantly different by LSD at the $5 \%$ level.

Comparison of sweet orange $\mathrm{P}$ uptake among the three treatments as a proportion of total $\mathrm{P}$ uptake shows that the value in the mycorrhizal treatment was the lowest and that the value in the control receiving no $\mathrm{P}$ fertilizer was the highest (Table 3). The AM contribution to P uptake was calculated to be $28 \%$, about half the value of the P fertilizer contribution to P uptake (Table 3). Arbuscular mycorrhizal inoculation significantly increased $\mathrm{P}$ uptake by $\mathrm{S}$. gracilis plants, with the AM contribution reaching 57\%, a value similar to that of the $\mathrm{P}$ fertilizer's contribution and representing about twice the AM contribution in sweet orange plants (Table 3).

\section{Root Distribution of Intercropped Plant Species as Influenced by AM Inoculation}

Total root length of $S$. gracilis was much longer than that of sweet orange (Table 4), but mean root diameter may also have been much smaller, taking

Table 2

Influence of AM inoculation and $\mathrm{P}$ fertilizer on $\mathrm{P}$ concentration $\left(\mathrm{mg} \mathrm{g}^{-1}\right)$ of intercropped sweet orange and $S$. gracilis

\begin{tabular}{llllll}
\hline & \multicolumn{2}{c}{ Sweet orange } & & \multicolumn{2}{l}{ Stylosanthes gracilis } \\
\cline { 2 - 3 } Treatment & Shoot & Root & & Shoot & Root \\
\hline Low P & $1.20 \mathrm{a}$ & $0.69 \mathrm{a}$ & & $2.91 \mathrm{a}$ & $0.81 \mathrm{a}$ \\
Low P + AM fungus & $1.24 \mathrm{a}$ & $0.82 \mathrm{ab}$ & & $3.39 \mathrm{ab}$ & $1.12 \mathrm{~b}$ \\
High P & $1.69 \mathrm{~b}$ & $0.94 \mathrm{~b}$ & & $3.95 \mathrm{~b}$ & $1.17 \mathrm{~b}$ \\
\hline
\end{tabular}

Values are the means of three replicates. Values in the same column followed by the same letter are not significantly different by LSD at the 5\% level. 


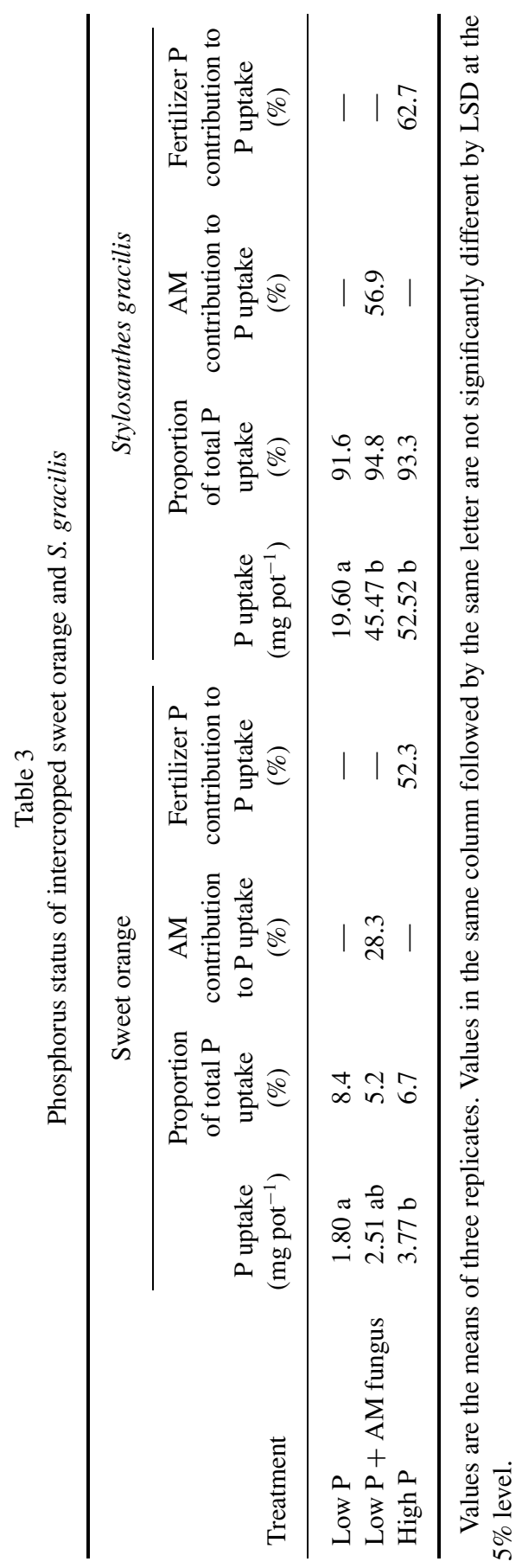


Table 4

Root length $(\mathrm{cm})$ of intercropped sweet orange and $S$. gracilis plants in both sides of the rhizobox

\begin{tabular}{lccccc}
\hline & \multicolumn{2}{c}{ Sweet orange } & & \multicolumn{2}{c}{ S. gracilis } \\
\cline { 2 - 3 } \cline { 5 - 6 } Treatment & $\begin{array}{c}\text { Sweet orange } \\
\text { side }\end{array}$ & $\begin{array}{c}\text { S. gracilis } \\
\text { side }\end{array}$ & & $\begin{array}{c}\text { Sweet orange } \\
\text { side }\end{array}$ & $\begin{array}{c}\text { S. gracilis } \\
\text { side }\end{array}$ \\
\hline Low P & $620 \mathrm{a}$ & $31 \mathrm{a}$ & & $1379 \mathrm{a}$ & $2875 \mathrm{a}$ \\
Low P + AM fungus & $726 \mathrm{a}$ & $13 \mathrm{a}$ & & $2670 \mathrm{~b}$ & $5149 \mathrm{~b}$ \\
High P & $734 \mathrm{a}$ & $36 \mathrm{a}$ & & $3116 \mathrm{~b}$ & $4414 \mathrm{~b}$ \\
\hline
\end{tabular}

Values are the means of three replicates. Values in the same column followed by the same letter are not significantly different by LSD at the $5 \%$ level.

the root dry weights into consideration. Neither P fertilizer nor AM inoculation significantly affected the root length of sweet orange plants, but both factors increased the root length of $S$. gracilis plants by 1.9-2.3 times on the sweet orange side of the rhizobox and 1.5-1.8 times on the $S$. gracilis side (Table 4). Interestingly, only $1.7 \%-4.7 \%$ of the total root length of sweet orange grew into the $S$. gracilis side, while $32.4 \%-41.4 \%$ of the total root length of $S$. gracilis grew into the sweet orange side (Figure 2). Visual observation also revealed that lateral roots of $S$. gracilis typically branched horizontally while those of sweet orange tended to branch vertically.

\section{Mycorrhizal Dependency and Phosphorus Status of Plant Species in Pot Culture}

In pot culture without root competition (Experiment 2), the proportion of sweet orange root length colonized by AM was lower than that of $S$. gracilis roots

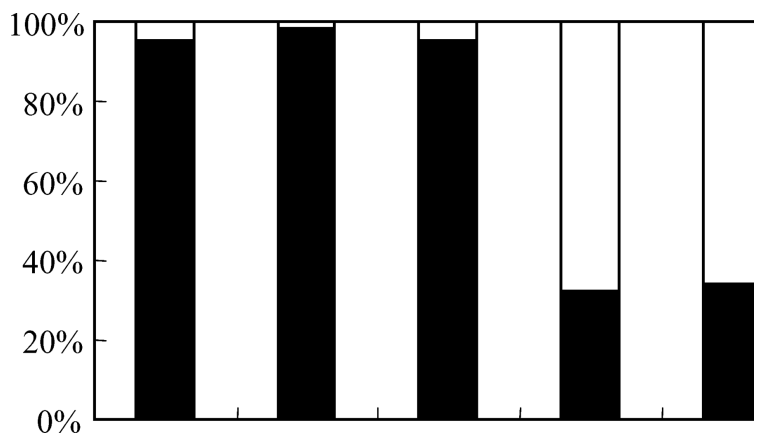

Figure 2. Proportion of plant roots (based on root length) in the soil volume of both sides of the rhizoboxes. Open bars and filled bars indicate the proportions in S.gracilis side and sweet orange side, respectively. 
(Table 5). Inoculation with the AM fungus led to a significant increase in biomass of $S$. gracilis, but not of sweet orange. The mycorrhizal dependency values of sweet orange and $S$. gracilis were calculated to be about $4.0 \%$ and $60 \%$. The contribution of AM inoculation to P uptake was $49 \%$ in sweet orange and $71 \%$ in S. gracilis (Table 5), and both values were higher than the corresponding values when the two plant species were intercropped in the first experiment (Table 3).

\section{DISCUSSION}

Numerous studies have been conducted out to evaluate the effects of AM inoculation on the growth of trees (Monzon and Azcon, 2001; Adjoud et al., 1996) or grasses (Wilson and Hartnett, 1998) as hosts. Tawaraya (2003) reviewed the mycorrhizal dependency values of 250 plant species and found that the mean values were $79 \%$ for tree species and more than $56 \%$ for all plants investigated. In the present experiment, the calculated mycorrhizal dependency of sweet orange was only $3.5 \%$, much lower than the value suggested by Tawaraya (2003). Many factors can influence mycorrhizal dependency, including plant P uptake efficiency (Yao et al., 2001a), P utilization efficiency (Baon et al., 1993), the P status of the soil (Plenchette and Morel, 1996), and carbohydrate allocation to roots (Yao et al., 2001b). Graham and Syvertsen (1985) demonstrated that plant growth rate could affect mycorrhizal dependency with citrus as host, and species with lower growth rates benefited less from AM inoculation. This result would seem to agree with the present experiment, in which the mycorrhizal dependency of sweet orange, a perennial tree species with a low growth rate, was much lower than that of S. gracilis, a herb with a high growth rate. On the other hand, similar kinds of plants can show a wide range of mycorrhizal dependency. For example, the mycorrhizal dependency of seven banana cultivars ranged from 5\% to 55\% (Declerck et al., 1995). Until now, there has been no published information on the mycorrhizal dependency of S. gracilis. Under our experimental conditions, the value was 59\%, indicating that an increase in plant biomass including root length (Table 2) occurred following AM inoculation. The large difference found in the mycorrhizal dependency of the two species may explain why sweet orange plants did not appear to benefit from AM inoculation when intercropped with $S$. gracilis.

Beneficial effects of mycorrhizae on plant growth often result mainly from increased $\mathrm{P}$ uptake; the contribution of AM to plant P uptake may, in turn, reflect the mycorrhizal dependency of the plant species in question. In our experiments, the AM contribution to P uptake of sweet orange and S. gracilis was $49 \%$ and $71 \%$, respectively, in monoculture (Table 5), and $28 \%$ and $57 \%$, respectively, (Table 3) with intercropping. The lower AM contribution in the intercropping system probably resulted from lower $\mathrm{P}$ application than that used in monoculture. It is worth noting that the AM contribution in sweet orange was about 


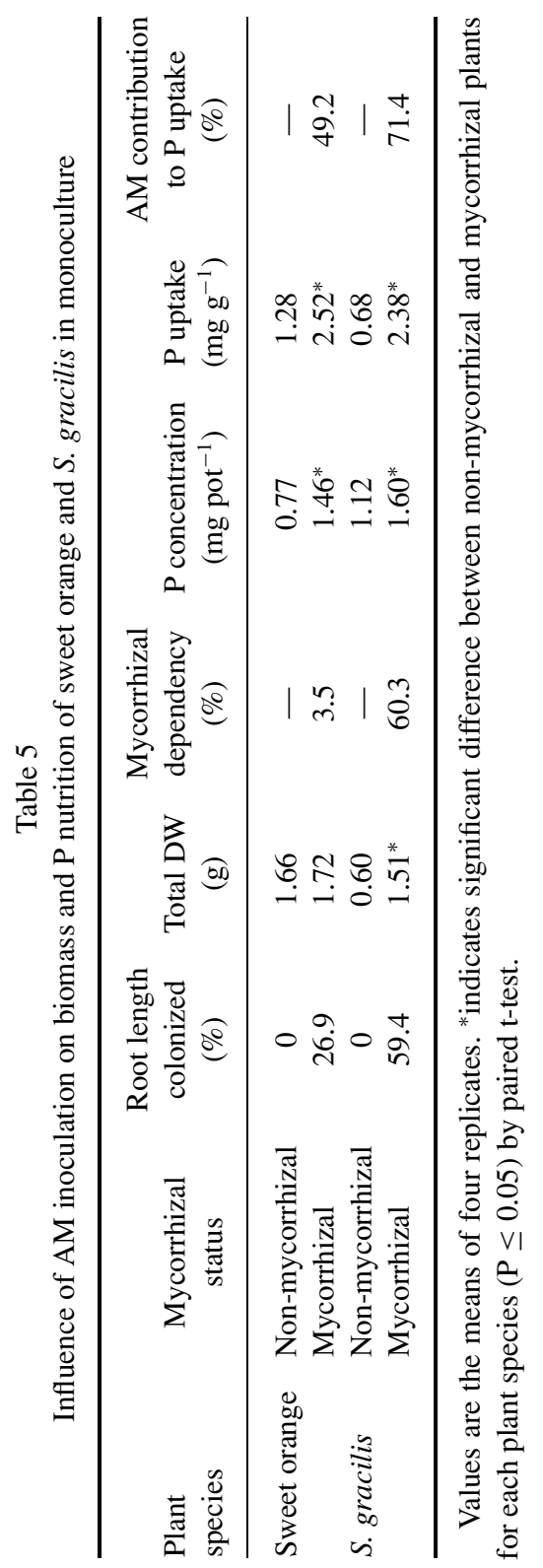


$70 \%$ of that in S. gracilis in monoculture, but only about $50 \%$ of that in the intercropping system. This result may indicate more extramatrical AM hyphae associated with $S$. gracilis roots and a greater root length induced by AM inoculation with intercropping. Fitter (1977) investigated the influence of AM inoculation on competition between two grasses and found that $\mathrm{P}$ was the primary factor mediating competition, although the AM contribution to plant $\mathrm{P}$ uptake was not reported. Van der Hejiden et al. (1998) also demonstrated in microcosms that AM hyphae and P levels in the soil mediated plant competition.

In these experiments, $\mathrm{AM}$ inoculation did not reduce competition and may have increased it (Table 3). In contrast, Sylvia et al. (2001) found that AM inoculation enhanced the competitive ability of tomato intercropped with bahiagrass at low or moderate soil P levels because tomato (Lycopersicon esculentum) shoot biomass was increased by $713 \%$ by AM colonization but only by $30 \%$ in bahiagrass. Allen and Allen (1990) suggested that mycorrhizal responsiveness was a good predictor of competitive interactions between plants, while Hetrick et al. (1989) clearly demonstrated a close relationship between mycorrhizal dependency and competitive ability of two tallgrass prairie grasses. In the work by Sylvia et al. (2001), the competitive advantage afforded by AM was eventually negated at high soil $\mathrm{P}$ levels, perhaps due to a decrease in mycorrhizal dependency. Experiments in the present study indicate that in addition to differences in mycorrhizal dependency, differences in root-system architecture may have mediated plant competitive ability (Table 4, Figure 2). Due to horizontal branching, more lateral roots of $S$. gracilis plants grew into the soil volume occupied by sweet orange plants, and consequently, may have competed more strongly for P. It is recognized that plants with horizontally branching root systems are more competitive for $\mathrm{P}$ than those with vertical branching (Lynch, 1995).

Grass or herb intercropping is a popular orchard-floor management technique in many countries. Although the AM fungus $G$. versiforme increased competition in the intercropping system with sweet orange and $S$. gracilis plants in this experiment, other fungal species may produce the reverse effect (Sylvia et al., 2001). Arbuscular mycorrhizal inoculation may be expected to exert a beneficial influence on fruit tree species in an intercropping system, which combines a suitable AM fungal species, a rootstock with high mycorrhizal dependency to the fungus, and a grass or herb species with low dependency to the fungus combined with vertical root branching.

\section{ACKNOWLEDGMENTS}

This research was funded by grant No. 30200006 from the National Natural Science Foundation of China, by grant No. EO5202480 from Guangdong Natural Science Foundation, and by the Foundation of South China Agricultural University. Experimental facilities were kindly provided by Guangdong Key Laboratory of Microbial Collection and Breeding. 


\section{REFERENCES}

Adjoud, D., C. Plenchette, R. Hallihargas, and F. Lapeyrie. 1996. Response of 11 eucalyptus species to inoculation with three arbuscular mycorrhizal fungi. Mycorrhiza 6: 129-135.

Allen, E. B., and M. F. Allen. 1990. The mediation of competition by mycorrhizae in successional and patchy environments. In Perspectives on plant competition, eds. J. B. Grace and D. Tilman, 367-389. San Diego, CA: Academic Press.

Baon, J. B., S. E. Smith, and A. M. Alston. 1993. Mycorrhizal responses of barley cultivars differing in P efficiency. Plant and Soil 157: 97-105.

Butler, J. D. 1986. Grass interplanting in horticulture cropping systems. HortScience 21: 394-397.

Camprubi, A., and C. Calvet. 1996. Isolation and screening of mycorrhizal fungi from citrus nurseries and orchards and inoculation studies. HortScience 31: 366-369.

Declerck, S., C. Plenchette, and D. G. Strullu. 1995. Mycorrhizal dependency of banana (Musa acuminata, AAA group) cultivar. Plant and Soil 176: $183-187$.

Fitter, A. H. 1977. Influence of mycorrhizal infection on competition for phosphorus and potassium by two grasses. New Phytologist 79: 119-125.

Graham, J. H., R. G. Linderman, and J. A. Menge. 1982. Development of external hyphae by different isolates of mycorrhizal Glomus spp. in relation to root colonization and growth of 'Troyer' Citrange. New Phytologist 91: $183-189$.

Graham, J. H., and J. P. Syvertsten. 1985. Host determinants of mycorrhizal dependency of citrus rootstock seedlings. New Phytologist 101: 667-676.

Haynes, R. J. 1980. Influence of soil management practice on the orchard agroecosystem. Agro-Ecosystems 6: 3-32.

Hetrick, B. A. D., G. W. T. Wilson, and D. C. Hartnett. 1989. Relationship between mycorrhizal dependence and competitive ability of two tallgrass prairie grasses. Canadian Journal of Botany 67: 2608-2615.

Hu, Y. L. 1998. Research progress in mycorrhizae of fruit trees in China. Journal of Fujian Agricultural University 1: 56-61 (in Chinese).

Klik, A., J. Rosner, and W. Loiskandl. 1998. Effects of temporary and permanent soil cover on grape yield and soil chemical and physical properties. Journal of Soil Water Conservation 53: 249-253.

Koske, R. E., and J. N. Gemma. 1989. A modified procedure for staining roots to detect VA mycorrhizas. Mycological Research 92: 486-505.

Lynch, J. 1995. Root architecture and plant productivity. Plant Physiology 109: $7-13$.

Monzon, A., and R. Azcon. 2001. Growth responses and N and P use efficiency of three Alnus species as affected by arbuscular mycorrhizal colonisation. Plant Growth Regulations 35: 97-104. 
Newman, E. I. 1966. A method of estimating the total length of root in a sample. Journal of Applied Ecology 3: 139-145.

Peng, S. B., D. M. Eissenstat, J. H. Graham, K. Williams, and N. C. Hodge. 1993. Growth depression in mycorrhizal citrus at high phosphorus supply: Analysis of carbon costs. Plant Physiology 101: 1063-1071.

Phillips, J. M., and D. S. Hayman. 1970. Improved procedures for clearing roots and staining parasitic and vesicular-arbuscular mycorrhizal fungi for rapid assessment of infection. Transactions of the British Mycological Society 55: $158-161$.

Plenchette, C., J. A. Fortin, and V. Furlan. 1983. Growth responses of several plant species to mycorrhizae in a soil of moderate $\mathrm{P}$ fertility. I. Mycorrhizal dependency under field conditions. Plant and Soil 70: 199-209.

Plenchette, C., and C. Morel. 1996. External phosphorus requirement of mycorrhizal and non-mycorrhizal barley and soybean plants. Biology and Fertility of Soils 21: 303-308.

Pool, R. M., R. M. Dunst, and A. N. Lakso. 1990. Comparison of sod, mulch, cultivation, and herbicide floor management practices for grape production in nonirrigated vineyards. Journal of American Society of Horticultural Science 115: 872-877.

Skroch, W. A., and J. M. Shribbs. 1986. Orchard floor management-An overview. HortScience 21: 390-394.

Smith, S. E., and D. J. Read. 1997. Mycorrhizal symbiosis, 2nd edition, 126159. London: Academic Press.

Sylvia, D. M., A. K. Alagely, D. O. Chellemi, and L. W. Demchenko. 2001. Arbuscular mycorrhizal fungi influence tomato competition with bahiagrass. Biology and Fertility of Soils 34: 448-452.

Tan, S. Y., and G. D. Crabtree. 1990. Competition between perennial ryegrass sod and 'Chardonnay' wine grapes for mineral nutrients. HortScience 25: 533-535.

Tawaraya, K. 2003. Arbuscular mycorrhizal dependency of different plant species and cultivars. Soil Science and Plant Nutrition 49: 655-668.

Thomas, R.L., R. W. Sheard, and J. R. Moyer. 1967. Comparison of conventional and automated procedures for nitrogen, phosphorus and potassium analysis of plant material using a single digestion. Journal of Agronomy 59: 240243.

Tworkoski, T. J., and D. M. Glenn. 2001. Yield, shoot and root growth, and physiological responses of mature peach trees to grass competition. HortScience 36: 1214-1218.

van der Heijden, M. G. A., J. N. Klironomos, M. Ursic, P. Moutoglis, R. Streitwolf-Engel, T. Boller, A. Wiemken, and I. R. Sanders. 1998. Mycorrhizal fungal diversity determines plant biodiversity, ecosystem variability and productivity. Nature 396: 69-72.

Walsh, B. D., S. Salmins, D. J. Buszard, and A. F. MacKenzie. 1996. Impact of soil management systems on organic dwarf apple orchards and soil 
aggregate stability, bulk density, temperature and water content. Canadian Journal of Soil Science 76: 203-209.

Welker, W. V., and D. M. Glenn. 1988. Growth responses of young peach trees and changes in soil characteristics with sod and conventional planting systems. Journal of American Society of Horticultural Science 113: 652656.

Wilson, G. W. T., and D. C. Hartnett. 1998. Interspecific variation in plant responses to mycorrhizal colonization in tallgrass prairie. American Journal of Botany 85: 1732-1738.

Yao, Q., X. L. Li, and P. Christie. 2001a. Factors affecting arbuscular mycorrhizal dependency of wheat genotypes with different phosphorus efficiencies. Journal of Plant Nutrition 24: 1409-1419.

Yao, Q., X. L. Li, G. Feng, and P. Christie. 2001b. Influence of extramatrical hyphae on mycorrhizal dependency of wheat genotypes. Communications in Soil Science and Plant Analysis 32: 3307-3317. 